\title{
Online Wavelet Denoising for a Quarter Car Model
}

\author{
Seda Postalcıoğlu \\ Abant İzet Baysal University \\ Faculty of Engineering and Architecture \\ Department of Electrical Electronics Engineering, Bolu, Türkiye
}

\begin{abstract}
Noise impact cannot be ignored in control system. In online systems when the received data by sensor contains noise, may cause to a problem. Linear position sensor can be widely used to control of body motion in different types of suspension system. Sensor's resolution, accuracy and stability depend on its electronics design. For this purpose, in this paper an online wavelet denoising has been studied for a quarter car model. Vibrations due to the unit step input are controlled with PID controller. If the sensor contains noise, controller performance will be poor. Online wavelet denoising is used to eliminate the noise. Simulation results show that when the system has online wavelet denoising, controller gives better results and system is not affected by the noise. As a result, this type of control strategy can be applied to the semi-active suspension systems to improve driver comfort.
\end{abstract}

\section{Keywords}

Wavelet denoising, PID control, vehicle safety.

\section{INTRODUCTION}

The transportation safety has been an active area of research in recent years. When a human is driving the transportation system, it involves reaction time, delay and human error that adversely affect safe driving [1]. At the same time constructed controls systems for vehicle comfort, sensor noise impact cannot be ignored. Noise can affects the system negatively and it causes undesirable situations. Thus this paper focus on the noise and to design the system with online wavelet denoising to eliminate the noise.

Real world data rarely comes clean. In order to extract useful information from raw data, robust denoising method is often required [2]. Wavelet is used frequently in data compression, auto industry, chemical process engineering, mathematics, image process, computer science and etc.[3].

As a recent studies, references [4],[5],[6],[7] could be demonstrated. In this study a quarter car model is used with MatLab-Simulink.

PID controller is studied for the displacement control. A closed loop system performs according to the data which is taken by sensor. Data received from the sensor contains the noise in the application and it affects the response of the controller negatively.

It is known that position and its derivatives, velocity and acceleration can be measured by using a linear position sensor. Semi-active suspension systems have a damper and the linear position sensor for controlling MR (Magnetorheological) fluid damper [8]. The linear position sensor can be widely used to control of body motion in different types of suspension system. Therefore noise, accuracy and stability of the linear position sensor are very crucial to control variable damping shock absorber in the semi-active suspension systems. Furthermore desired performance from the suspension systems in terms of minimum percentage overshoot and rapid stabilizing time can be reached by using optimum controller and mathematical model [9],[10],[11]. The focus of this study is to improve a riding comfort and road handling for road disturbance by using online wavelet denoising.

This paper is divided into the following parts. In section 2 , system model is presented. Section 3 is devoted to the description of the online wavelet denoising. In section 4 the simulation results are given.

\section{SYSTEM MODEL}

When the degrees of freedom increases for the vehicle, it makes the study complicated. In this study, online wavelet denoising is examined for $2 \mathrm{DoF}$ vehicle model.

A quarter car model is examined with PID controller for the displacement. The linear quarter car model is given in Fig. 1 [12],[13],[14],[15]

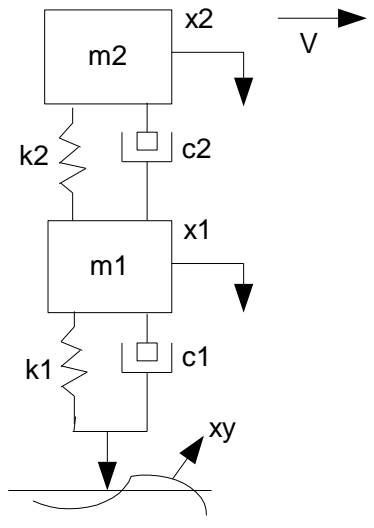

Fig 1: A quarter car model [12],[13],[14],[15]

The mass $\mathrm{m} 1$ represents approximately the mass of the wheel plus part of the mass of the suspension arms, $\mathrm{m} 2$ represents approximately $1 / 4$ of the body mass $[15,16]$. K2 means spring coefficient of the suspension systems, $\mathrm{k} 1$ represents spring coefficient of the rubber tires, $\mathrm{c} 2$ and $\mathrm{c} 1$ shows suspension damping coefficient and rubber tires damping coefficient, respectively. Vibration movements are shown with $\mathrm{x} 1$ and $\mathrm{x} 2$. Road roughness is used as xy. The linear equations of motions of the system model are given in equation (1) [14].

$\left[\begin{array}{cc}m_{1} & 0 \\ 0 & m_{2}\end{array}\right]\left[\begin{array}{c}\ddot{x}_{1} \\ \ddot{x}_{2}\end{array}\right]+\left[\begin{array}{cc}C_{1}+C_{2} & -C_{2} \\ -C_{2} & C_{2}\end{array}\right]\left[\begin{array}{c}\dot{x}_{1} \\ \dot{x}_{2}\end{array}\right]+\left[\begin{array}{cc}k_{1}+k_{2} & -k_{2} \\ -k_{2} & k_{2}\end{array}\right]\left[\begin{array}{l}x_{2} \\ x_{1}\end{array}\right]=\left[\begin{array}{l}0 \\ k_{1}\end{array}\right]\left(x_{y}\right)+\left[\begin{array}{l}0 \\ C_{1}\end{array}\right]\left[\begin{array}{l}\dot{x}_{y} \\ y\end{array}\right.$

\section{ONLINE WAVELET DENOISING}

With reasons such as vehicle vibration, excitation of road, the signal can be severely polluted. Various techniques have been used to process the signal, such as fast Fourier Transform and Neural Network [17]. In this study wavelet denoising method is used. Daubechies wavelet is chosen. Fig.2 shows the db7 wavelet. 


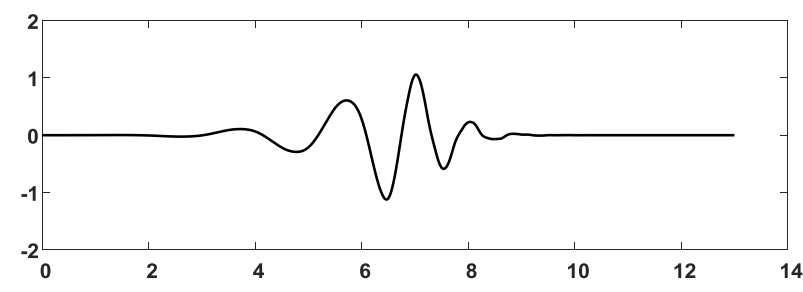

Fig 2: db7 wavelet

In most cases, wavelet denoising is performed as offline processing for real-time signals [18]. A moving window technique is to solve this problem [3]. In this paper online wavelet denoising method is used for the system control.
At the first stage of online denoising, when sampled data are not long enough for a wavelet transform, the data is kept. As soon as the minimum length is reached, the first window initiates and online denoising begins. Subsequently, the window moves ahead step by step with the width fixed $[18,19]$.

Fig. 3 shows the designed of the system block diagram. cd and ca are the detail and approximation coefficients. $\mathrm{H}$ and $\mathrm{L}$ are the high-pass and low-pass filters, respectively. The filter coefficients for the decomposition and the reconstruction stages are seen in table 1 .

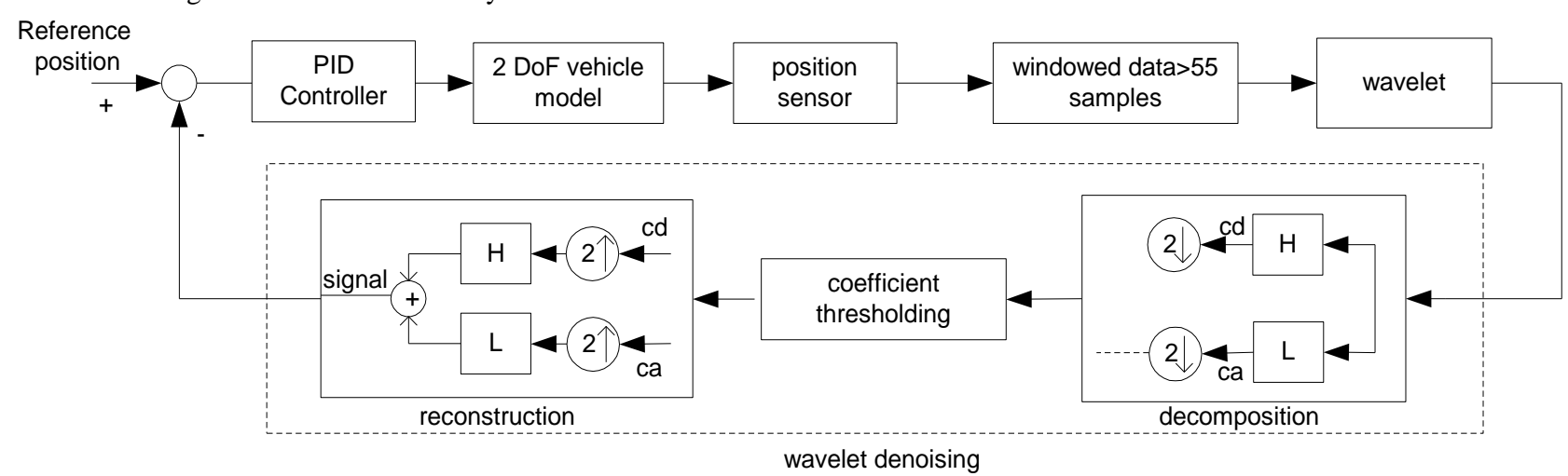

Fig 3: The designed of the system block diagram

Table 1. The filter coefficients for the decomposition and the reconstruction stages

\begin{tabular}{|l|l|l|l|}
\hline $\begin{array}{l}\text { Decomposition } \\
\text { low-pass filter }\end{array}$ & $\begin{array}{l}\text { Decomposition } \\
\text { high-pass filter }\end{array}$ & $\begin{array}{l}\text { Reconstruction } \\
\text { low-pass filter }\end{array}$ & $\begin{array}{l}\text { Reconstruction } \\
\text { high-pass filter }\end{array}$ \\
\hline 0.0004 & -0.0779 & 0.0779 & 0.0004 \\
\hline-0.0018 & 0.3965 & 0.3965 & 0.0018 \\
\hline 0.0004 & -0.7291 & 0.7291 & 0.0004 \\
\hline 0.0126 & 0.4698 & 0.4698 & -0.0126 \\
\hline-0.0166 & 0.1439 & -0.1439 & -0.0166 \\
\hline-0.0380 & -0.2240 & -0.2240 & 0.0380 \\
\hline 0.0806 & -0.0713 & 0.0713 & 0.0806 \\
\hline 0.0713 & 0.0806 & 0.0806 & -0.0713 \\
\hline-0.2240 & 0.0380 & -0.0380 & -0.2240 \\
\hline-0.1439 & -0.0166 & -0.0166 & 0.1439 \\
\hline 0.4698 & -0.0126 & 0.0126 & 0.4698 \\
\hline 0.7291 & 0.0004 & 0.0004 & -0.7291 \\
\hline 0.3965 & 0.0018 & -0.0018 & 0.3965 \\
\hline 0.0779 & 0.0004 & 0.0004 & -0.0779 \\
\hline & & & \\
\hline & & & \\
\hline & & & \\
\hline & & & \\
\hline & & & \\
\hline & & & \\
\hline & & & \\
\hline & & & \\
\hline
\end{tabular}

The technique contains of applying a discrete wavelet transform to the original data. The detail wavelet coefficients are thresholded and inverse transforming the thresholded coefficients to obtain the denoised data [20],[21],[22]. Hard and Soft thresholding methods are generally used for the wavelet coefficients. References [23],[24] gives the details about the wavelet denoising. In this study hard thresholding is used. After the reconstruction stage a denoised signal is obtained. Using the denoised signal, system is performed successfully.

\section{SIMULATION RESULTS}

The simulation results are obtained using Matlab/Simulink. The numerical values for the quarter car parameters are shown in table 2. [15]

Table 2. The numerical values for the quarter car parameters

\begin{tabular}{|l|l|l|}
\hline Parameter & value & Units \\
\hline M2 & 229 & $\mathrm{~kg}$ \\
\hline M1 & 31 & $\mathrm{~kg}$ \\
\hline K2 & 20000 & $\mathrm{~N} / \mathrm{m}$ \\
\hline K1 & 120000 & $\mathrm{~N} / \mathrm{m}$ \\
\hline
\end{tabular}

For this study the quarter car model is controlled with PID controller. Fig. 4 shows the PID control effects.

When the step function is applied to the quarter car model, the result includes the oscillation. If the system has a PID Controller, the result has no oscillation. 


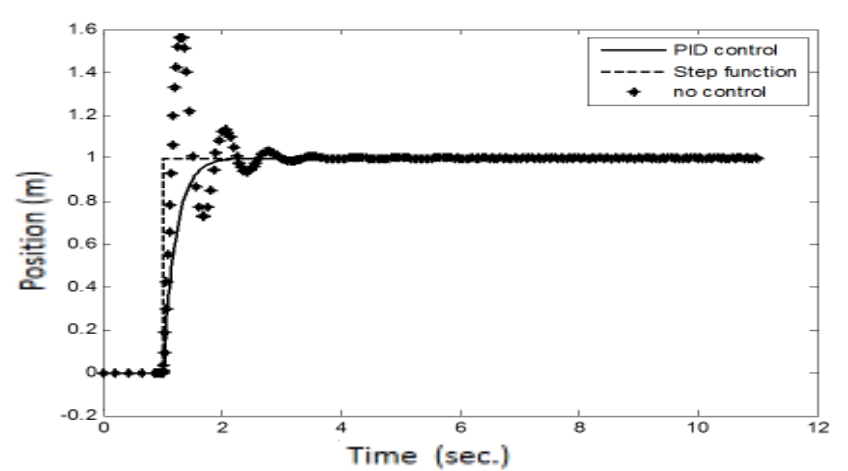

Fig 4: Step function response for the system

Data is taken by the sensor with the noise. Sensor noise is taken into consideration for the study. The noise has 0.15 variance. The data which has noise is shown in fig. 5 for the study.

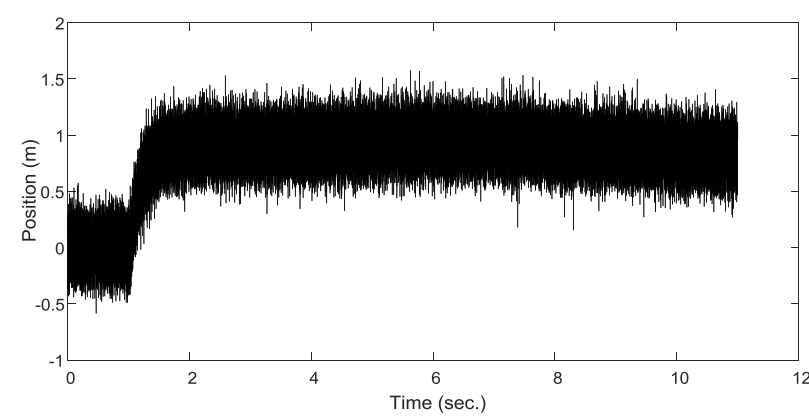

Fig 5: The data with the noise

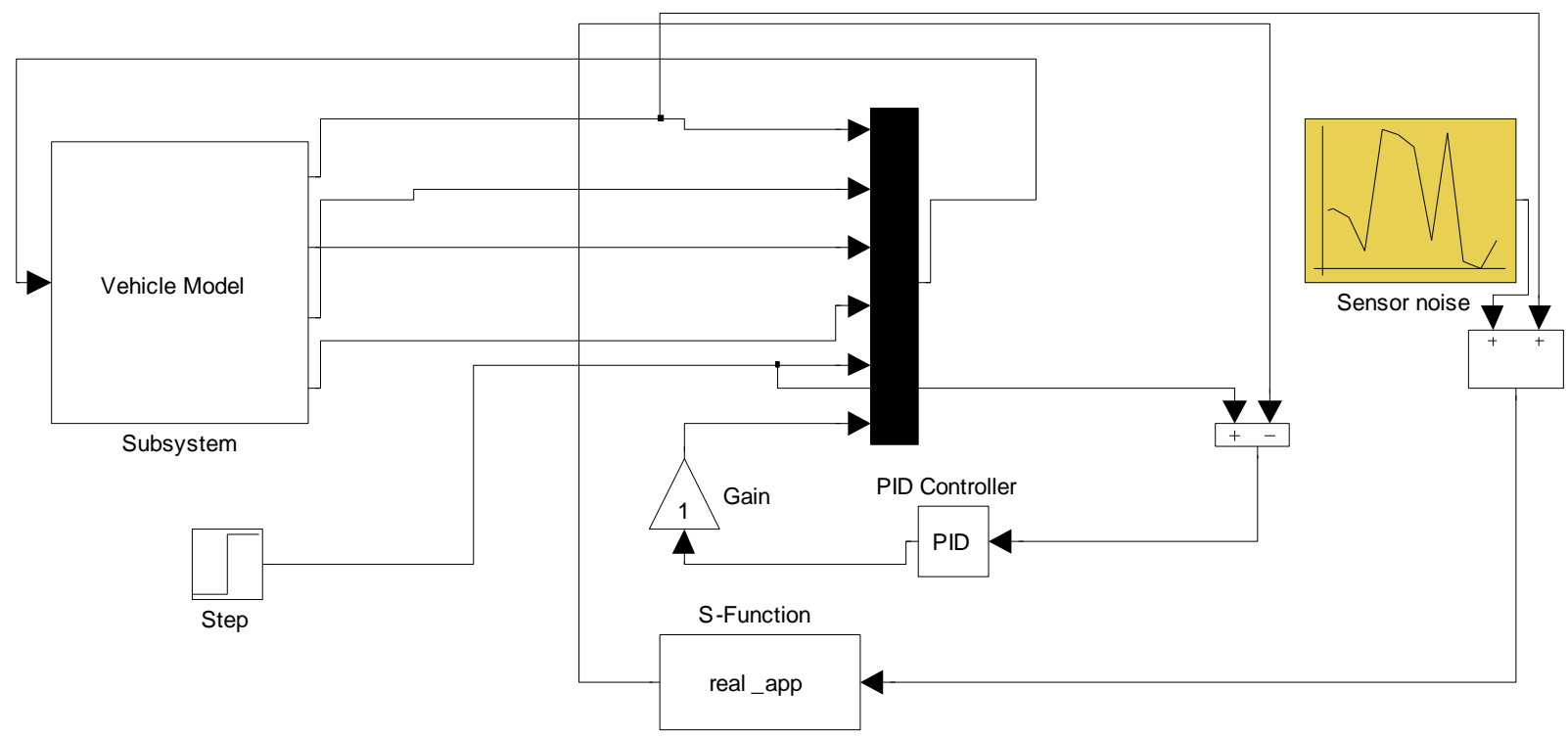

Fig 7: The quarter car model with online wavelet denoising

Finally, the quarter car model with online wavelet denoising is constructed as shown in fig. 7. Fig. 8 represents the response of the system using online wavelet denoising. It is clear that although the system has a sensor noise, PID controller makes the control properly.
Fig. 6 shows the response of the system without online wavelet denoising. The sensor noise effects the PID controller badly, so the system response is not good for the control.

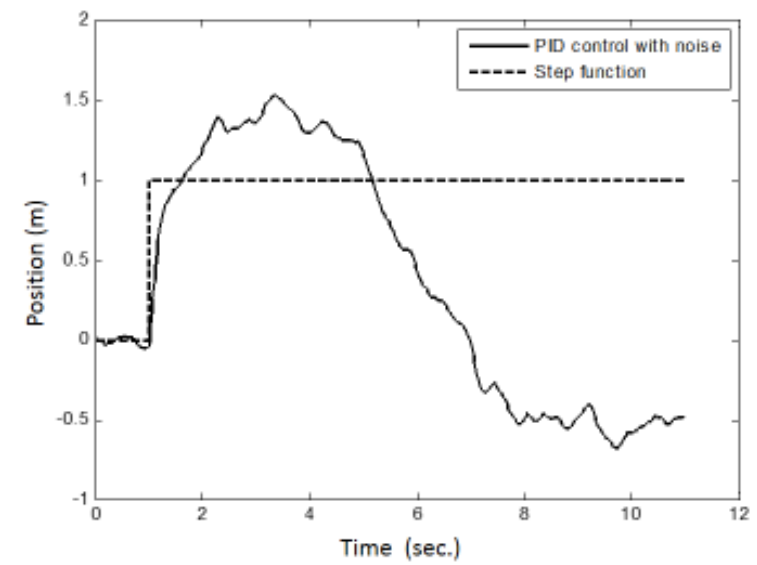

Fig 6: The response of the system without online wavelet denoising

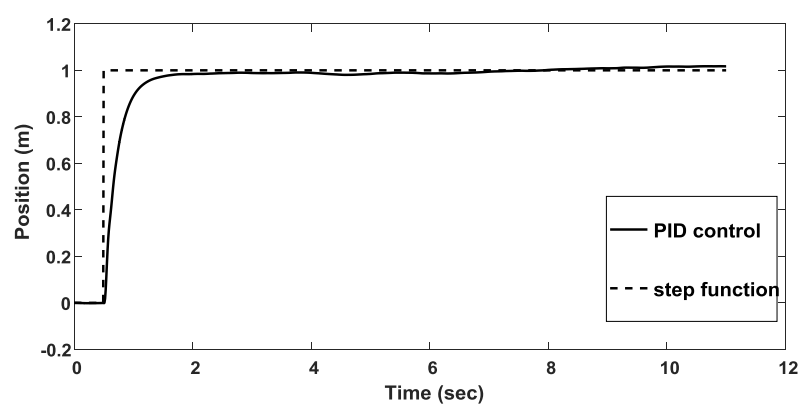

Fig 8: The response of the system with online wavelet denoising 


\section{CONCLUSIONS}

In this study a quarter car model is used with MatLabSimulink. Vibrations due to unit step input are examined to control with PID controller. A closed loop system performs according to the data which is taken by sensor. Data received from the sensor contains the noise in the application. To solve this problem online wavelet denoising is studied. It is observed that online wavelet denoising can be effectively used in real time control applications. Additionally some parameters are made adjustable according to the real time conditions such as wavelet basis, window width, thresholding type. Simulation results show that the effectiveness of the online wavelet denoising for controlling of body motion, improving the ride comfort. This study demonstrates that the noise effects can be minimized and the controller performances can be much better. The future scope of this study is to determine the parameters of online wavelet denoising using artificial intelligence techniques.

\section{REFERENCES}

[1] Lin C.M.,Chen C.H.,Car-Following Control Using Recurrent Cerebellar Model Articulation Controller, IEEE transactions on vehicular technology, vol. 56, no. 6, pp:3660-3673. 2007.

[2] Yang R, Ren M, Wavelet denoising using principal component analysis. Expert Systems with Applications 38, 1073-1076,2011.

[3] Qibing J, Sajid K, General theory on online wavelets denoising based on moving window. International Conference on Technological Advances in Electrical, Electronics and Computer Engineering (TAEECE), 157 - 161, 9-11 May 2013

[4] Qifeng F., Guoqing C. and Zibo S., Application of Wavelet De-Noising Method in vibration signal analysis of Elevator Car,13th International Conference on Ubiquitous Robots and Ambient Intelligence (URAl), pp:610-614. August 19-22, 2016 at Sofitel Xian on Renmin Square, Xian, China.

[5] Chetan R.G, Both-Rusu R., Dulf E.-H., Festila C., Physical Model of a Quarter-Car Active Suspension System, Carpathian Control Conference (ICCC), 2017 18th International, pp:517-520,28-31 May 2017, Romania.

[6] Mahajan B. D., Divekar A.A., Modeling and System Identification of a Quarter car Suspension using Simulink, IEEE International Conference On Recent Trends In Electronics Information Communication Technology,pp:180-183. May 20-21, 2016, India

[7] Vidya V., Dharmana M.M., Model Reference Based Intelligent Control of an Active Suspension System for Vehicles, International Conference on circuits Power and Computing Technologies [ICCPCT],pp:1-5. 20-21 April 2017, India

[8] Ericksen E O and Faramarz G., A Magneto-Rheological Fluid Shock Absorber for an Off-Road Motorcycle,. International Journal of Vehicle Design, 33(1): 139-152, 2003

[9] Qazi A J, Khan A, Khan M T, Noor S, A Parametric Study on Performance of Semi-Active Suspension System with Variable Damping Coefficient Limit, AASRI Procedia 4, $154-159,2013$.
[10] Sánchez E A, A quarter-car suspension system: car body mass estimator and sliding mode control, Procedia Technology 7, $208-2142013$.

[11] Fang Z, Shu W, Du D, Xiang B, He Q, He K, Semiactive Suspension of a Full-vehicle Model based on Double-loop Control, Procedia Engineering 16, 428 437, 2011

[12] Krauze, P., Kasprzyk, J. Neural Network Based LQ Control of a Semiactive Quarter-Car Model, 18th International Conference on Methods and Models in Automation and Robotics (MMAR), 189 - 194, 26-29 Aug. 2013.

[13] Wagner U V, On non-linear stochastic dynamics of quarter car models, International journal of non-linear mechanics 39, 753-765, 2004

[14] Verros G, Natsiavas S, Papadimitriou C, Design Optimization of quarter car models with passive and semi active suspensions under random road excitation. Journal of Vibration and Control 11,581-606, 2005.

[15] Gobbi M, Mastinu G, Analytical description and optimization of the dynamic behaviour of passively suspended road vehicles. Journal of sound and vibration 245(3), 457-481, 2001

[16] Gobbi, M., Levi F., Mastinu G., "Multi-objective stochastic optimisation of the suspension system of road vehicles", Journal of Sound and Vibration 298 pp:10551072,2006

[17] Shi X, Zhao X, Hui F, Yang L, Processing of Hydraulic pressure sensor signal based on wavelet analysis. 2012 International conference on applied physics and industrial engineering. International Conference on Applied Physics and Industrial Engineering, Physics Procedia 24, 2143-2150, 2012.

[18] Rui X, Ke M, Feng Q, Zhen Lei W, Online wavelet denoising via a moving window. Acta Automatica Sinica Vol.33, No:9,897-901, 2007.

[19] Liu Z. , Mi Y. , Mao Y., An Improved Real-time Denoising Method Based on Lifting Wavelet Transform Measurement Science Review, Volume 14, Issue 3, Pages 152-159,2014.

[20] Shu-Jen Steven Tsai, Power Transformer Partial Discharge (PD) Acoustic Signal Detection using Fiber Sensors and Wavelet Analysis, Modeling and Simulation, Master of Science, the faculty of the Virginia Polytechnic Institute and State University,2002.

[21] Kamath C., Baldwin C.H., Fodor I.K., Tang N.A., "Design and implementation of a parallel object-oriented image processing toolkit," Proc. SPIE 4118, Parallel and Distributed Methods for Image Processing IV, 9 October 2000.

[22] Postalcığlu, S., Erkan, K., Doğru Bolat E., "Comparison of Kalman Filter and Wavelet Filter for Denoising", Proc. of 2005 Int. Conference on Neural Networks and Brain, ICNNB’05, vol 1-3, 951-954, China,2005.

[23] Postalcioğlu, S., Erkan, K., Doğru Bolat E., "Discrete Wavelet Analysis Based Fault Detection", WSEAS Transactions on Systems, Issue 10, Volume 5, 23912397,2006 